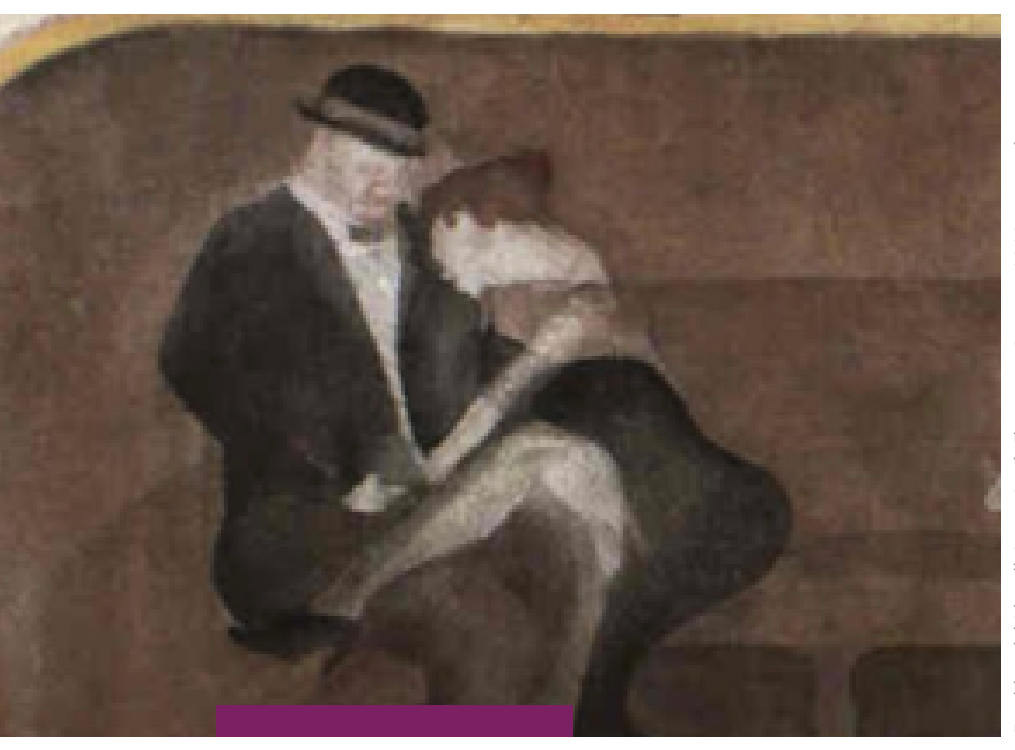

FIGURAS REVISTA ACADÉMICA DE INVESTIGACIÓN ISSN 2683-2917

Vol. 2, núm. 2, marzo-junio 2021

https://doi.org/10.22201/fesa.figuras.2021.2.2

Esta obra está bajo una licencia

Creative Commons Atribución-NoComercialCompartirlgual 4.0 Internacional

\section{La prostitución como principal actividad económica para el establecimiento de la ciudad de Mexicali a inicios del siglo Xx}

\section{Prostitution as the Main Economic Activity for the Foundation of Mexicali's City in the Early 2oth Century}

https://doi.org/10.22201/fesa.figuras.2021.2.2.147

\section{Iván Alexis Roldán-Mendoza}

El Colegio de México. Centro de Estudios

Demográficos, Urbanos y Ambientales

Lorenia Ruiz Muñoz, en el libro Un pequeño Montecarlo en el desierto. Mexicali 1901-1913, establece que la prostitución se desarrolló como una actividad económica próspera para el desarrollo de Mexicali; en su investigación analiza diversos archivos históricos de inicios del siglo $\mathrm{xx}$.

\section{Un pequeño Montecarlo}

Mexicali es una ciudad mexicana que se localiza en la frontera con Estados Unidos, al extremo noroeste del Valle que le dio nombre. Según el Censo de Población y Vivienda hecho por el Instituto Nacional de Estadística y Geografía (INEGI) en 2010, la población total de la capital del estado de Baja California era de 936826 habitantes, que representaba el $29.7 \%$ de la población total de este estado. El presente de la ciudad fronteriza contrasta con sus inicios a principios del siglo $\mathrm{xx}$, pues, en palabras de la autora Lorenia Ruiz Muñoz, en aquellos días sólo había "unas cuantas ramadas, algunos indios «bravos» y un calor sofocante" (Ruiz 2017, 57).

A lo largo de cinco capítulos, más la introducción y reflexiones finales, la autora despierta la curiosidad del lector porque explica cómo Mexicali dejó de ser una tierra desértica para convertirse en sede de actividades relacionadas con los vicios, en especial la prostitución. Para tratar el tema, el libro comienza por describir la prostitución en México entre finales del siglo XIX y comienzos del siglo xx, pasa por la presentación de archivos históricos que muestran el crecimiento de la actividad prostibularia en los inicios de la ciudad fronteriza y termina con exponer la función de la prostitución en la consolidación de la ciudad. La exposición de fotografías históricas de los inicios de Mexicali permite imaginar las relaciones sociales que el libro narra en aquellos días.

La prostitución, que se define como "el comercio habitual que hace una mujer de su cuerpo" (Ruiz 2017, 15-16), era parte de la vida pública de México a principios del siglo xx. Por un lado, la necesidad de mujeres dedicadas a tal actividad correspondía a una doble moral de la sociedad mexicana, donde el impulso sexual de las mujeres se negaba y el de los hombres se reconocía; por otro, la prostitución, por ser una actividad pública, estaba regulada y era fácil identificar a las prostitutas y los prostíbulos. La prostitución en Mexicali se encontraba en medio 
de dos ideologías acerca de su regulación: la tolerancia mexicana y la prohibición estadounidense. La autora cuestiona la creencia de que fueron empresarios extranjeros los que iniciaron el mercado de ocios y vicios en la frontera, pues en su investigación encontró que los primeros que lucraron con tales actividades fueron mexicanos.

El trabajo sexual se relacionaba con la propagación de enfermedades y, por lo tanto, se lo consideraba un problema de salud pública. La reglamentación de la actividad prostibularia era necesaria para controlar las enfermedades sexuales y recaudar fondos para el erario; la autora menciona tres ideologías que proponían diferentes maneras de actuar ante la prostitución: el reglamentarismo, que tenía a la prostitución por un mal necesario y, por tanto, debía regularse; el abolicionismo, que pretendía la desaparición total de la prostitución por la ineficacia del reglamentarismo; y el prohibicionismo, que responsabilizaba a las prostitutas de los vicios, la inmoralidad y la degradación de las buenas costumbres, por lo que buscaba desaparecer tal actividad.

Los trabajos de irrigación, que buscaban aprovechar las aguas del Río Colorado, causaron el surgimiento de Mexicali en el año de 1901. El constante desbordamiento del río provocó la llegada de trabajadores que participaban en las obras relacionadas con el uso del agua. Junto con el desarrollo de los trabajos del Río Colorado se establecieron comercios, como cantinas, sitios de apuestas y prostíbulos, que prosperaron a tal punto que se convirtieron en las principales fuentes de aportación al erario. La cercanía de Mexicali con la ciudad estadounidense de Caléxico influyó en que las prostitutas estadounidenses se asentaran en Mexicali, lo que intensificó los sitios que se dedicaban a los vicios; el libro hace un buen trabajo al demostrar cómo la diferencia entre la gestión de la prostitución de ambos países contribuyó a que en Mexicali prosperara el trabajo sexual.

Con el inicio de la Revolución Mexicana, la inestabilidad política se presentó en el Distrito Norte de Baja
California. Para tal fecha, la prostitución en Mexicali, que aumentó por las medidas prohibicionistas en California, representaba la actividad más lucrativa de todo el distrito. La renuncia de Porfirio Díaz a la presidencia, en el año de 1911, obligó a renovar a los funcionarios de Baja California. El nuevo jefe político del distrito fue el general Manuel Gordillo Escudero. El hecho de que familias mexicanas vivieran en Caléxico, a causa del aumento de las actividades relacionadas con los vicios en Mexicali, preocupó al jefe político, por lo que seis meses después de su nombramiento prohibió la prostitución. Sin embargo, ante los grandes beneficios que se obtenían del trabajo sexual, los negocios optaron por operar furtivamente.

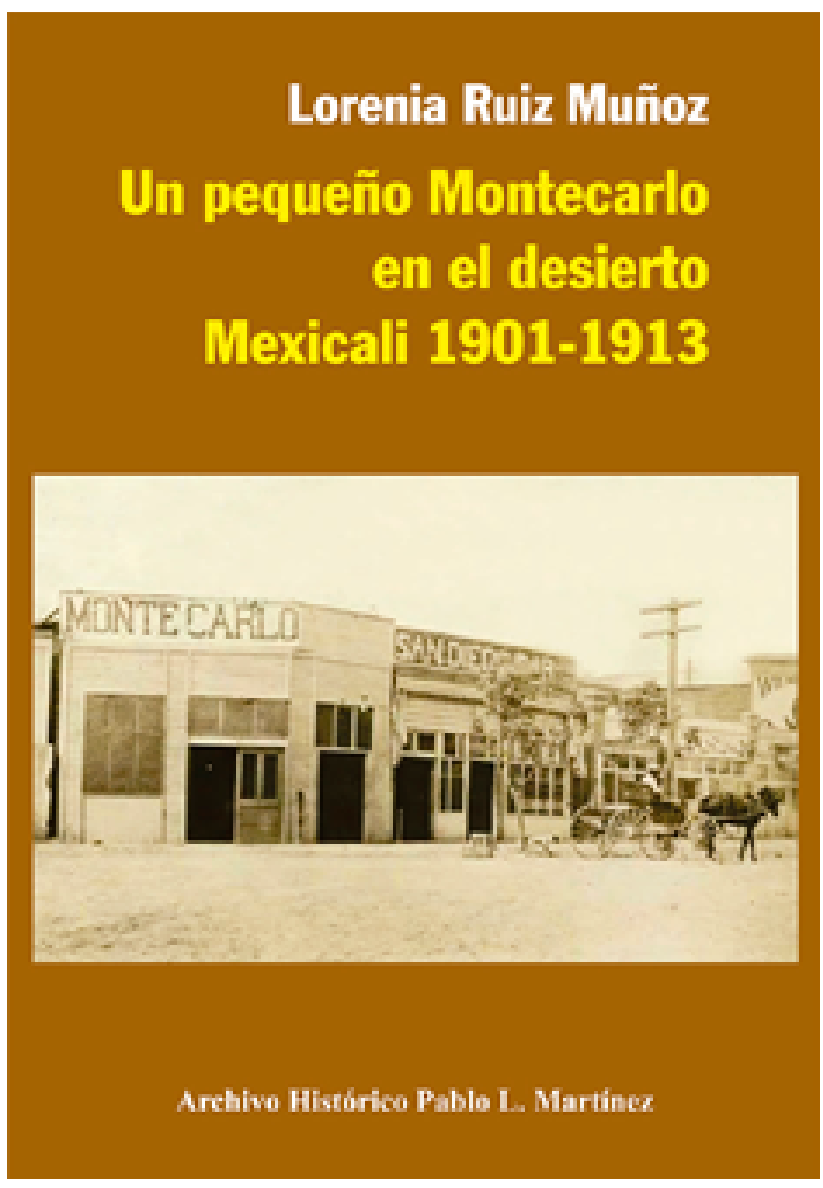

Portada del libro Un pequeño Montecarlo en el desierto. Mexicali 1901-1913, de Lorenia Ruiz Muñoz, Archivo Histórico Pablo L. Martínez. 
El libro presenta una investigación histórica bastante completa que merece el esfuerzo de estudiarse pues, a partir del análisis de documentos históricos, muestra los nombres de las prostitutas y el monto de los impuestos que pagaban; además, ofrece información sobre cuántos comercios que se relacionaban con los vicios había y explica la relación entre la prostitución y el gobierno para entender cómo funcionaba el trabajo sexual en Mexicali. A manera de ejemplo, el capítulo cuatro que se intitula "El caso Maxime Brown", en el que la autora relata el abuso de poder y complicidad entre el sub-inspector de inmigración de Mexicali, Javier Velasco, y la prostituta extranjera Maxime Brown. Tal capítulo plantea que "las ganancias obtenidas por los negocios furtivos, entre ellos el lenocinio, eran de tal magnitud que la justicia se orientaba más por defender esos intereses que la aplicación correcta de la ley" (Ruiz 2017, 153).

Las autoridades no lograron erradicar la corrupción presente en los negocios furtivos; al contrario, provocaron que las autoridades abusaran de su poder y atropellaran a aquellos que participaban en el trabajo sexual. Para 1913, incluso se justificaba la presencia de los prostíbulos con el argumento de "ser el estilo de vida de Mexicali" (Ruiz 2017, 172). La revisión de los documentos históricos también demostró la presencia de prostitutas negras en Mexicali, lo que ofrece información para posteriores investigaciones que traten la relación de la raza y la prostitución en la ciudad fronteriza de inicios del siglo $\mathrm{xx}$, pues tal tema ha tenido poca consideración en los estudios sobre la prostitución en Mexicali.

Éste es un libro que desmitifica los primeros años de Mexicali pues, con el análisis de archivos históricos, se encontró que la ciudad fronteriza tenía más relación con la prostitución que con los trabajos en las obras de irrigación. El libro vincula los temas urbanos con los históricos en el estudio del surgimiento de una ciudad, muestra el efecto que tiende a establecer políticas públicas opuestas en la conformación del perfil económico de una localidad para el caso del
Distrito Norte de la Baja California, donde la prostitución es clave para entender su proceso de urbanización. El libro indica dos periodos en la administración de Mexicali; el primero, en el que mexicanos poseían prostíbulos y también ejercían algún cargo público, y el segundo, donde los extranjeros eran los que lucraban con el trabajo sexual. Tales periodos muestran, por un lado, la corrupción y el conflicto de intereses de las autoridades -ya que poseían prostíbulos- y, por otro, la complicidad del gobierno con los extranjeros para obtener alguna ganancia del trabajo sexual.

La investigación de Ruiz Muñoz desmitifica que el surgimiento y urbanización de las ciudades fronterizas de México a inicios del siglo xx fue a causa de las obras de riego de la época; en cambio, plantea que fueron las actividades ilegales -como la prostitución, los juegos de azar o las cantinas- las que provocaron el dinamismo económico. El texto recopila valiosa información histórica sobre la prostitución en la frontera norte de México y, al mismo tiempo, permite analizar la política pública para regular las actividades que se relacionan con los vicios y la corrupción de la que eran parte los dirigentes de aquellos días. Sin duda, ésta es una lectura recomendable para quienes se interesan en estudiar el desarrollo de la prostitución en México o en conocer la historia de Mexicali.

Referencia

Ruiz Muñoz, Lorenia. 2017. Un pequeño Montecarlo en el desierto. Mexicali 1901-1913. La Paz, Baja California Sur: Gobierno del Estado de Baja California Sur-Secretaría de Cultura-Instituto Sudcaliforniano de CulturaArchivo Histórico Pablo L. Martínez. 